\title{
The Madrid Protocol: Mewujudkan Perlindungan Hukum Yang Efektif Bagi Merek Terkenal di ASEAN
}

\author{
Rohaini
}

DATA NASKAH

Masuk: 6 Nopember 2017

Diterima: 17 April 2017

Terbit: 1 Juni 2018

KORESPONDEN PENULIS:

Fakultas Hukum Universitas Lampung Jalan Sri Soemantri Brojonegoro No. 1 Gedong Meneng, Bandar Lampung E-mail: rohaini.arifien81@gmail.com

\begin{abstract}
The systems of Intellectual Property Rights protection are teritorial. R egistration process and law anforcement should be done separately in each of yurisdiction concerned. In the field of Trademark Rights, it is often become a challenge of its law enforcement. In practice, it is often a well-known mark is used without permission by the parties whose not entittled due to the mark has not been regeistered. This condition occurs in ASEAN region, as an example is V iet $\mathrm{N}$ am. In V ietnam, it will be very easy to find the missapropriation of well-known marks by certain partiesdue to the mark is not registered in V iet $\mathrm{N}$ am. The M adrid Protocol, which is an improvement of M adrid A greement, since its appearance in 1989, be coming an alternative in establishing the international registration system. It offers convinience ways for the owner of trademarks for protecting their marks all over the world (member of the Protocol) with just one application and one procedure through the WIPO International Berau for reviewing and proceeds to destination countries.
\end{abstract}

K eywords: Intellectual Property Rights, L egal Protection, Trademark Rights, The Madrid Protocol

\begin{abstract}
ABSTRAK
Sistem perlindungan $\mathrm{H}$ ak Kekayaan Intelektual bersifat teritorial. Pendaftaran dan penegakan hukum harus dilakukan secara terpisah dimasing-masing yuridiksi bersangkutan. Pada rezim merek, sistem ini seringkali menjadi tantangan tersendiri bagi penegakan hukum merek. Dalam praktek, seringkali sebuah merek dengan reputasi terkenal (wellknown trademarks) digunakan tanpa izin bahkan didaftarkan oleh pihak yang tidak berhak hanya karena merek tersebut belum terdaftar dinegara tersebut. Kondisi inipun terjadi di kawasan ASEAN. Ambil contoh V ietnam, di Vietnam akan sangat mudah ditemukan penggunaan merek-
\end{abstract}


merek terkenal tanpa izin oleh pihak-pihak tertentu dengan sangat bebas karena tidak didaftarkannya merek tersebut di Vietnam. Protokol Madrid yang merupakan penyempurnaan dari the $M$ adrid $A$ greement, sejak kemunculannya tahun 1989 merupakan sebuah alternatif dalam membangun sistem perndaftaran internasional. Sistem ini menawarkan kemudahan bagi pemilik merek untuk mendapatkan proteksi atas mereknya di seluruh dunia (negara anggota Protokol) hanya dengan satu aplikasi dan satu prosedur melalui W IPO International Berau untuk dilanjutkan ke negara-negara tujuan.

$\mathrm{K}$ ata kunci: Perlindungan $\mathrm{H}$ ukum, M erek Terkenal, M adrid Protokol, Pendaftaran M erek Internasional

\section{PENDAHULUAN}

Merek merupakan bagian penting dan pokok yang berfungsi sebagai identitas suatu barang atau jasa. Lewat merek, konsumen mampu mengidentifikasi dan membedakan suatu barang atau jasa dari suatu produsen. Selain bermanfaat untuk konsumen, bagi perusahaan merek berfungsi sebagai tanda untuk membedakan asal-usul, citra, reputasi maupun bonafiditas diantara perusahaan sejenis yang satu dengan yang lainnya. Tentu saja hal ini menjadi penting, mengingat merek barang atau jasa yang teridentifikasi baik oleh masyarakat, secara tidak langsung akan memberikan kontribusi terhadap pengembangan citra perusahaan tersebut.

Kawasan Asia Tenggara sendiri bagi produsen merupakan sebuah market yang sangat besar. Dengan jumlah penduduk yang mencapai lebih dari 600 juta jiwa dan dengan angka pertumbuhan ekonominya yang mencapai 4.8\% tahun 2016 benar-benar mengiurkan secara ekonomi (Secretariat of ASEAN, 2016). Selain itu, pertumbuhan pendapatan di kawasan Asia Tenggara yang semakin tinggi menjadikan jumlah masyarakat kelas menengah (middle class) dikawasan ini semakin meningkat. Banyak alasan mengapa tidak sedikit industri memanfaatkan merek-merek terkenal untuk digunakan tanpa izin pada produk-produknya. Salah satunya adalah agar mudah dijual. Dengan menggunakan merek terkenal produk barang atau jasa baru tak perlu repot-repot mengurus nomor pendaftaran ke Dirjen $\mathrm{HKI}$ atau mengeluarkan uang jutaan rupiah untuk membangun citra produknya (brand image). Mereka tidak perlu repot-repot membuat divisi riset dan pengembangan untuk dapat menghasilkan produkyang selalu up to date, karena mereka tinggal menjiplak produk orang lain dan untuk pemasarannya biasanya sudah ada 'kelompok' yang siap untuk menerima produk hasil tiruan tersebut. Selain itu juga suburnya praktek 'ilegal' ini karena didukung oleh tingginya daya beli konsumen yang pas-pasan tetapi ingin tampil trendi.

Guna memenuhi kebutuhan kaum kelas menegah ini, pelaku bisnis lokalpun mulai melakukan mix products. Sudah umum bila pelaku bisnis tersebut mulai melihat keluar kawasan Asia Tenggara sebagai sumber 'inspirasi' . Hal ini menjadi tendesi bagi mereka untuk memproduksi barang asli tapi palsu (imitasi) dari suatu produk terkenal ataupun produk yang sedang berkembang di luar kawasan Asia Tenggara. Fenomena ini pada akhirnya menyebabkan pemilik merek terkenal seringkali dihadapkan pada kenyataan pahit ternyata produk mereka telah ditiru atau merek mereka ternyata telah terdaftar atas nama pengusaha lokal disuatu negara.

Secara umum, perlindungan hukum atas penggunaaan merek di negara-negara Asia Tenggara yang tergabung dalam Association of Southeast Asian Nations (ASEAN) sendiri saat ini menunjukan kesamaan sistem. Umumnya sistem yang digunakan adalah sistem first to file/first come, first served (Vachanavuttivong, 2016). Sistem ini sendiri mengakibatkan secara umum merek yang tidak terdaftar di negara ASEAN secara otomatistidak akan dilindungi di ASEAN. Ada dugaan inilah yang menyebabkan tingginya fenomena pendaftaran merek terkenal oleh pihak yang tidak seharusnya.

M enyikapi fenomena tersebut, sejumlah pedoman regional di kawasan ASEAN telah dibentuk, diantaranya Common Guidelines for the Subtantive Examination of Trademarks (Common Guidelines), ASEAN Database on Intellectual Property, the ASEAN TM View, dan melakukan pembaharuan terhadap Undang-Undang M erek. Selain itu, negara-negara ASEAN juga berkomitmen untuk melaksanakan the Madrid Protocol pada tahun 2015. Dengan melaksanakan Protocol ini, pemilik nantinya cukup melakukan satu kali pendaftaran merek dalam rangka untuk mendapatkan perlindungan di seluruh negara anggota Protokol. 


\section{RUMUSAN MASALAH}

1. Bagaimanakah gambaran perlindungan hukum merek terhadap merek terkenal (well-known trademarks) di negara-negara ASEAN?

2. Bagaimanakah keutamaan the M adrid Protocol dalam mewujudkan sebuah sistem perlindungan hukum yang efektif bagi merek terkenal di kawasan ASEAN?

\section{METODE PENELITIAN}

Penelitian ini merupakan penelitian yang mengkaji studi dokumen, yakni menggunakan berbagai data sekunder seperti peraturan perundang-undangan, keputusan pengadilan, teori hukum, dan dapat berupa pendapat para sarjana. Penelitian jenisnormatif ini menggunakan analisis kualitatif yakni dengan menjelaskan data-data yang ada dengan katakata atau pernyataan bukan dengan angka-angka. Pendekatan penelitian dilakukan secara konseptual (conceptual approch), pendekatan perundang-undangan (statue approach), serta pendekatan komparatif (comparative approch) (Soerjono dan Mamuji, 2001: 14). Pendekatan secara konseptual dilakukan karena penelitian ini ditujukan untuk mempelajari kebijakan baru terkait sistem pendaftaran merek secara internasional. Oleh karena itu, pemahaman terhadap pandangan/doktrin yang berkembang dalam ranah hak kekayaan intelektual umumnya, dan hukum merek khususnya sangat perlu dilakukan. Pemahaman yang komprehensif ini selanjutnya akan menjadi menjadi pijakan untuk membangun argumentasi hukum terkait keutamaan M adrid Protocol sebagai dasar pemberlakukan kebijakan sitem pendaftaran merek secara internasional, dan efektivitas sistem baru ini dalam memproteksi merek terkenal di ASEAN.

Pendekatan secara komparatif (comparative approch) pada penelitian ini akan dilakukan mengingat objek penelitian ini adalah seluruh negara-negara ASEAN yang secara regulasi memiliki sistem perlindungan merek yang berbeda-beda. Pendekatan perundang-undangan (statue approach) adalah pendekatan terakhir yang akan digunakan dalam penelitian ini terutama undang-undang/regulasi terkait merek yang berlaku di negara-negara ASEAN. Hal ini wajib dilakukan mengingat setiap negara di ASEAN memiliki regulasi yang berbeda dalam memproteksi merek di negaranya. Dengan melakukan kajian terhadap regulasi ini, diharapkan penulis akan dapat mendapatkan sebuah pemahaman terkait kebijakan nasional apa yang harus dilakukan oleh masingmasing negara di ASEAN untuk mengharmonisasikan sistem pendaftaran Merek di Madrid Protokol dalam undangundang merek di tiap-tiap negara.

\section{IV.HASIL PENELITIAN DAN ANALISIS}

\section{A. Protocol Relating to the Madrid Agree- ment Concerning The International Registra tion Of Marks (Madrid Protocol)}

Madrid Protocol merupakan perjanjian internasional yang disepakati oleh negara anggota WIPO pada tahun 1989 sebagai dasar hukum pembentukan Sistem Madrid (Madrid System) untuk pendaftaran internasional merek. Dengan adanya Sistem M adrid, para negara anggota dapat mendaftarkan mereknya di semua negara anggota hanya dengan satu kali pendaftran di kantor merek negaranya (Ali, 2008: 9).

Permohonan pendaftaran merek internasional tersebut harus berdasarkan pada satu atau lebih pendaftaran pada Negara peserta Protocol di mana Pemohon tinggal, berbisnis atau berkewarganegaraan. Permohonan tersebut harus diajukan melalui Kantor MerekNegara tersebut. Kantor M erek akan memeriksa detail dari permohonan internasional tersebut termasuk kesamaannya dengan aplikasi atau pendaftaran pada Negara tersebut selanjutnya mengirim ke WIPO International Bureau (IB). IB tidak melakukan pemeriksaan substantif. IB hanya melakukan pemeriksaan formalitas termasuk juga biaya, pengklasifikasian merek berdasarkan Nice Agreement. Apabila ada ketidaksesuaian maka IB akan memberitahukan Kantor Merek Negara asal dan atau Pemohon, dan memberikan waktu untuk perbaikan. Apabila tidak ada ketidaksesuaian atau perbaikan sudah dilakukan maka IB akan mendaftar merek tersebut pada International Register, memberitahukan Kantor M erek Negara asal dan mengirim sertifikat pendaftaran pada pemegang. IB juga akan mempublikasikan pendaftaran pada Berita Resmi WIPO atas merek internasional dan mengirim detail ke Negaranegara tujuan. Masing-masing Negara tujuan akan memeriksa International Registration berdasarkan UndangUndang Mereknya masing-masing.

A pabila ada keberatan atau oposisi maka Negara tujuan 
akan memberi tahu IB yang akan menyampaikan kepada Pemegang Merek. Selanjutnya penyelesaian akan diteruskan dengan melalui bantuan agen merek lokal. Berdasarkan Madrid Protocol, Kantor M erek harus mengeluarkan penolakan dalam jangka waktu 12 bulan dengan pilihan perpanjangan 6 bulan. Apabila tidak ada penolakan dalam 12 atau 18 bulan maka merek harus mendapatkan perlindungan. Tujuan yang hendak dicapai dari Perjanjian Madrid adalah mempermudah cara pendaftaran merek-merek di berbagai negara dan juga menghindarkan pemberitahuan asal barang secara palsu. Indonesia sendiri sampai saat ini belum masuk sebagai anggota Perjanjian Madrid.

Keunggulan International Registration of Marks berdasarkan Protokol Madrid adalah sebagai berikut:

1. Kepraktisan

2. Penghematan dari sisi anggaran, karena baik biaya pendaftaran maupun biaya perpanjangan hanya dilakukan satu kali

3. Penghematan waktu, karena begitu didaftarkan pada IB di WIPO, maka otomatis berlaku bagi semua negara pihak dalam protokol ini

4. Perluasan Perlindungan pada negara baru yang bergabung dalam sistem ini

5. Adanya pilihan kepada para pendaftar merek mengenai filing date, berdasarkan pada national applications atau berdasarkan pada national registrations

6. Adanya waktu pemeriksaan yang lebih panjang yakni 18 (delapan belas) bulan, sehingga memberikan keleluasaan waktu pada setiap kantor pendaftaran merek di negara pihak

7. Tersedianya database merek yang terdaftar melalui mekanisme M adrid System secara detail dan online pada website WIPO

8. Adanya pemasukan pendapatan melalui "individual fee" untuk Kantor Pendaftaran merek di negara pihak yang menjadi tempat tujuan pendaftaran merek

9. Adanya mekanismetransformasi untuk setiap merek yang telah terdaftar di WIPO selama masa percobaan 5 (lima) tahun sejak filling date di international registration mendapat klaim dari negara asal atau office of origin dan terbukti sehingga pendaftaran mereknya harus dibatalkan. M ekanisme transformasi diberi waktu 3 (tiga) bulan sejak tanggal pembatalan, tanpa registrasi ulang seperti pada awal pendaftaran merek, filling date dihitung berdasarkan pendaftaran pertama, dan tanpa biaya pendaftaran lagi (Hidayati dan Ester, 2017: 178).

\section{B. ASEAN dan Intellectual Property}

The Association of Southeast Asian Nations (ASEAN) adalah sebuah organisasi internasional yang didirikan di Bangkok pada 8 Agustus 1967 atas inisisasi beberapa negara di Asia Tenggara yaitu Indonesia, Malaysia, Filipina, Singapura, dan Thailand. Secara historis, pembentukan ASEAN dilatarbelakangi karena adanya kepentingan dan tujuan yang sama dari negara-negara tersebut, menciptakan perdamaian dan stabilitas ekonomi dan politik di kawasan Asia Tenggara. Saat ini hampir seluruh negara di Asia Tenggara telah menjadi anggota ASEAN, yaitu Brunei Darussalam, Kamboja, Indonesia, Lao PDR, M alaysia, M yanmar, Filipina, Singapura, Thailand, dan Vietnam.

Berawal pada KTT yang dilaksanakan di Kuala Lumpur pada tanggal 1997, sebagaimana tercantum dalam ASEAN Vision 2020 disepakatilah ASEAN untuk menjadi suatu kawasan makmur, stabil dan sangat bersaing dalam perkembangan ekonomi yang berlaku adil dan dapat mengurang kesenjangan dan kemiskinan sosial ekonomi dengan cara membentuk sistem perdagangan bebas atau free trade antara negara-negara anggota ASEAN .

Sejalan dengan tujuan yang hendak dicapai, akan banyak juga tantangan-tantangan yang dihadapi, termasuk dalam bidang perlindungan terhadap intellectual property (IP). Sebagaimana di Kelompok Masyarakat Uni Eropa (the European Union), arus barang (arus manusia, arus jasa, dan arus modal) bebas keluar masuk di kawasan ini. Kondisi ini tentu tidak akan jauh berbeda dialami oleh ASEAN ketika MEA diberlakukan. Untuk mengontrol efek samping dari kebebasan ini, khususnya dalam bidang IP, perlu dikembangkan sebuah sistem yang dapat memberikan perlindungan intellectual property lintas batas.

Secara umum, menyikapi permasalahan komersialilasi hak kekayaan intelektual di kawasan Asia Tenggara, sebenarnya telah dilakukan berbagai upaya, diantaranya:

1. M elaksanakan Rencana Aksi Kekayaan Intelektual ASEAN 2004-2010 (rencana aksi) dan Rencana Kerja untuk Kerja 
sama Hak cipta ASEAN (rencana kerja);

2. Membentuk sebuah sistem pengarsipan ASEAN untuk desain dalam rangka memfasilitasi pengajuan oleh pengguna dan meningkatkan koordinasi kantor-kantor IP antara ASEAN M ember States (AMS);

3. Untuk menyetujui perjanjian internasional yang sama, termasuk the Madrid Protocol;

4. Untuk mempertahankan konsultasi dan pertukaran informasi di antara lembaga penegak nasional dalam perlindungan intellectual property rights; dan

5. Untuk mempromosikan kerja sama regional dalam intellectual property rights baru seperti pengetahuan tradisional, sumber daya genetik dan ekspresi budaya tradisional (Dirjen Kerjasama Perdagangan Internasional, 2011: 65).

Khusus dalam bidang perlindungan hukum merek, telah disiapkannya sejumlah petunjuk teknis pemeriksaan subtantive merek yang dituangkan dalam The Common Guidelines for the Subtantive Examination of M ark. Dikembangkan pula beberapa perangkat pendukung, termasuk the SouthEast Asia TM View.

Selain ASEAN TM View, untuk mengoptimalkan sistem pendaftaran dan perlindungan terhadap merek di ASEAN, dikembangkan pula ASEAN TM Class yang merupakan database online yang dapat diakses dalam 7 bahasa nasional. ASEAN TM Class merupakan media konsultasi gratis yang menawarkan aktivitas pemrosesan ke database yang berisikan sekumpulan istilah yang diterima oleh Kantor Kekayaan Intelektual di ASEAN yang berpartisipasi dalam pemilihan istilah yang autentik untuk keperluan identifikasi barang dan jasa serta untuk keperluan pendaftaran merek. M elalui ASEAN TM Class pemilik merek yang akan mendaftar dapat mencari dan memverifikasi pengklasifikasian istilah yang benaruntuk keperluan merek pada barang atau jasa sesuai dengan kriteria yang telah ditentukan oleh Klasifikasi International (Nice Agreement).

Selain itu, dalam 5 tahun terakhir, beberapa negara dikawasan ASEAN tercatat telah menyetujui sejumlah perjanjian internasional yang dikeluarkan WIPO terkait pendaftaran IP, diantaranya the Patent Coperation Treaty Organization, the Madrid Protocol, and the Hague Agreement. Saat ini negara ASEAN yang telah bergabung dalam
Protokol Madrid antara lain: Singapura. Kamboja, Laos, Vietnam, Filipina, dan terakhir Indonesia.

\section{Perlindungan terhadap Merek Terkenal (WellKnown Marks)}

M erek dagang merupakan bagian penting dari identitas produk barang dan jasa. M erek membantu masyarakat untuk mengenali kwalitas produk sejenis. M erekjuga dapat menjadi alat untuk membangun kepercayaan, reputasi dan membangun loyalitas konsumen. M erek memberikan fungsi untuk membedakan satu produk terhadap produk sejenis lain dengan memberikan tanda pembeda. Tanda pembeda tersebut dapat berupa gambar, warna, logo, nama, kata, angka, atau kombinasi dari hal-hal tersebut. Dibeberapa negara ASEAN, seperti Singapura, Brunei Darusalam, M alaysia, Laos, Kamboja, Vietnam, dan Thailand bahkan memasukan bentuk3D kemasan suatu barang ke dalam perlindungan rezim Merek.

Berdasarkan reputasi (reputation) dan kemasyhuran (reknown) suatu merek, merek dibedakan ke dalam tiga kategori yaitu merek biasa (normal marks), merek terkenal (well-known marks), dan merek termasyhur (famous marks) (Harahap, 1996). Suatu merek dapat dianggap terkenal bukan hanya merek yang dimiliki oleh pihak asing saja tetapi juga merek-merek lokal yang dimiliki oleh para pengusaha nasional yang dianggap terkenal oleh kalangan tertentu, atau masyarakat pada umumnya.

Penentuan mengenai terkenal tidaknya suatu merek di satu negara dengan negara yang lain berbeda-beda. Beberapa negara mengizinkan pemilik merek terkenal cukup mendaftarkan mereknya sehingga mendapatkan sertifikat merek terkenal. Sementara dikebanyakan negara-negara yang lain, terkenal atau tidak sebuah merek ditetapkan berbedabeda case by case didasarkan pada proses pemeriksaan sebuah sengketa merek atau berdasarkan pengujian admintrasi. Dalam hal ini, alat bukti yang sering kali digunakan sebagai pengukur keterkenalan suatu produk barang atau jasa adalah penjualan (sales), iklan (advertising) dan besar pendapatan (revenue figures), luas wilayah pemakaian (geographical scope of use), saluran perdagangan (channels of trade), banyaknya jumlah pendaftaran yang dilakukan dinegara lain (registrations in home and other countries), catatan keberhasilan pemenuhan hak atas merek (past enforcement efforts), dan juga tingkat 
pengenalan produk tersebut oleh masyarakat (the results of consumer recognition surveys) (International Trademark Associaton,.

WIPO sendiri pada Article 2 Joint Recommendation Concerning Provisions on the Protection of Well-Known Marks menyebutkan beberapa faktor yang dapat dipergunakan untuk mempertimbangkan terkenal atau tidaknya suatu merek, yaitu:

(1) Factors for Consideration

a) In determining whether a mark is a well-known mark, the competent authority shall take into account any circumstances from which it may be inferred that the mark is well known;

b) In particular, the competent authority shall consider information submitted to it with respect to factors from which it may be inferred that the mark is, or is not, well known, including, but not limited to, information concerning the following:

1. The degree of knowledge or recognition of the mark in the relevant sector of the public;

2. The duration, extent, and geographical area of any use of the mark;

3. The duration, extent and geographical area of any promotion of the mark, including advertising or publicity and the presentation, at fairs or exhibitions, of the goods and/or services to which the mark applies;

4. The duration and geographical area of any registrations, and/or any applications for registration, of the mark, to the extent that they reflect use or recognition of the mark;

5. The record of successful enforcement of rights in the mark, in particular, the extent to which the mark was recognized as well known by competent authorities;

6. The value associated with the mark.

\section{Perlindungan Hukum Merek Terkenal (WellKnown Marks) di NegaraNegara ASEAN}

Dalam rangka perlindungan terhadap merek dagang yang akan dipasarkan di ASEAN, setiap merek dagang haruslah didaftarkan dan teregistrasi disetiap negara anggota ASEAN. Namun demikian, beberapa negara anggota ASEAN telah menandatangani dan menjadi anggota the $M$ adrid Protocol. Dengan meratifikasi Protokol, melalui single application sistem, nantinya pelaku usaha cukup mendaftarkan merek dagangnya di salah satu negara anggota ASEAN saja.

\section{Brunei Darussalam}

Ketentuan hukum merek di Brunei Darussalam dapat ditemukan pada the Trade M arks Order 1999. UndangUndang M erek ini sejatinya hasil adopsi dari the English Trade M ark Act 1994. Berdasarkan the Trade M arks Order 1999, merek di Brunei dibedakan menjadi tiga yaitu, merek dagang, merek jasa dan merek kolektif. Lebih lanjut, secara administrasi apabila suatu merek dibuat dalam bentuk menggunakan karakter lain diluar huruf romawi/alpabet Inggris, contohnya huruf Chinese atau Jepang atau huruf Arab, maka huruf-huruf tersebut harus diterjemahkan ke dalam bahasa lokal.

Terhadap perlindungan merek terkenal, hukum positif Brunei secara tegas memberikan perlindungan terhadap setiap merek yang dianggap sebagai merek terkenal berdasarkan the Paris Convention dan merupakan kepunyaan warga negara yang merupakan salah satu anggota the Paris Convention, seseorang yang berdomisili atau seseorang yang memiliki usaha atau kegiatan perdagangan disalah satu negara anggota the Paris Convention, sejauh yang bersangkutan melakukan kegiatan bisnis dan memiliki niat baik (good will) di negara Brunei Darussalam. Sementara untuk klasifikasi kelas barang dan Jasa, Negara Brunei merujuk pada the International Classification of Goods and Services Systems yang terdapat dalam the Nice Agreement. Brunei Darussalam sendiri secara resmi bergabung sebagai anggota M adrid Protokol pada 6 Januari 2017. Secara general penegakan hukum yang lemah terkait pelanggaran merek merupakan alasan mengapa praktek penggunaan merek terkenal tanpa izin masih marak terjadi.

\section{Kamboja}

Hak merek akan diberikan terhadap merek yang berwujud kata-kata dan simbol yang secara visual memiliki perbedaan atau dapat membedakan dengan merek dagang tau merek 
jasa yang satu dengan yang lain. Undang-Undang M erek juga memungkinkan pendaftaran bagi merek kolektif, merek dagang, dan indikasi geografis. M eskipun tidak dinyatakan dalam undang-undang, M erek 3D juga dimungkinkan untuk didaftarkan (sepanjang memenuhi persyaratan-persyaratan yang ditentukan dan memiliki daya pembeda). Negara Kamboja menganut sistem pendaftaran merek the first-tofile principle.

Berdasarkan Undang-Undang Merek Kamboja, The Law Concerning M arks, Trade Names and Acts of Unfair Competition sebagaimana telah mengalami amandemen pada tanggal 7 Februari 2002, pengakuan perlindungan terhadap merek terkenal dapat ditemukan pada beberapa pasal, diantaranya Article 4, Article 14, Article 25 and Article 26 of The Law Concerning M arks, Trade Names and Acts of Unfair Competition. Wujud pelindungan sebagaimana disebutkan meliputi:

1. Penggunaaan merek terkenal yang terdaftar ataupun tidak terdaftar di Kamboja, baik sama secara keseluruhan maupun sama pada pokoknya akan dikategorikan sebagai pelanggaran bilamana penggunaan merek tersebut tanpa disertai surat persetujuan dari pemilik merek terkenal tersebut (Law Concerning M arks of Cambodia, art. 2526).

2. Pendaftaran sebuah merek dagang atau jasa akan ditolak apabila merek tersebut memiliki kesamaan secara keseluruhan maupun sama pada pokoknya, atau merupakan terjemahan dari sebuah merek dagang yang terkenal di Kamboja (Law Concerning Marks of Cambodia, art. 4).

3. Sebuah merek dagang yang memiliki kesamaan secara keseluruhan maupun sama pada pokoknya dengan merek terkenal berdasarkan permohonan dari Kementerian Perdagangan dapat dilakukan pembatalan (Law Concerning M arks of Cambodia, art. 14).

Dalam praktek, kriteria yang dipakai untuk menentukan terkenal tidaknya suatu merek didasarkan pada Article 2 J oint Recommendation Concerning Provisions on the Protection of Well-Known Marks. Dalam rangka memperkuat penegakan hukum merek, pemerintah Cambodia sendiri Juni 2015 telah tercatat sebagai anggota dari the Madrid Protocol. M eskipun demikian, dalam pelaksanaannya masih ditemukan kesenjangan-kesenjangan hukum yang signifikan (significant gaps) dan ketidakpastian dalam penerapan dan peng-interpretasi-an ketentuan, khususnya terhadap definisi terkenal tidaknya suatu merek.

\section{Indonesia}

Secara yuridis, rezim merek di Indonesia didasarkan pada Undang-Undang Nomor 20 Tahun 2016 tentang M erek dan Indikasi Geografis. Undang-undang ini memungkinkan bentuk (shapes) 2D/3D, hologram dan suara dilindungi dalam rezim merek. Namun demikian, rezim merek dilndonesia belum mengakui aroma (smell) sebagai bagian dari merek dagang. Sistem pendaftaran merek di Indonesia menganut sistem 'first-to-file'.

Pengakuan dan perlindungan terhadap merek terkenal dapat ditemukan pada Pasal 21 Undang-Undang Nomor 20 Tahun 2016 tentang M erek dan Indikasi Geografis. Pasal ini secara tegas mengamanatkan bahwa permohonan pendaftaran sebuah merek akan ditolak jika merek tersebut mempunyai persamaan pada pokoknya atau keseluruhannya dengan merek terkenal milik pihak lain untuk barang dan/ atau jasa sejenis. Selain pasal tersebut, Pasal 83 UndangUndang Nomor 20 Tahun 2016 tentang Merek dan Indikasi Geografis memberikan hak kepada pemilik merek terkenal untuk mengajukan Gugatan kepada Pengadilan Niaga berupa ganti rugi dan/atau penghentian semua perbuatan yang berkaitan dengan penggunaan sebuah merekterkenal kepada pihak lain yang secara tanpa hak menggunakan merek tersebut baik sama pada pokoknya maupun sama secara keseluruhan.

Mengenai merek terkenal sendiri, hukum merek di Indonesia tidak secara tegas mendefinisikan apa itu merek terkenal. Berdasarkan Penjelasan Pasal 21 ayat (b) UndangUndang Nomor 20 Tahun 2016 tentang M erek dan Indikasi Geografis, parameter merek terkenal untukbarang dan/atau jasa yang sejenis dilakukan dengan memperhatikan pengetahuan umum masyarakat mengenai M erek tersebut di bidang usaha yang bersangkutan. Di samping itu diperhatikan pula reputasi Merek terkenal yang diperoleh karena promosi yang gencar dan besar-besaran, investasi di beberapa negara di dunia yang dilakukan oleh pemiliknya dan disertai bukti pendaftaran M erek tersebut di beberapa 
negara. A pabila hal-hal di atas belum dianggap cukup, Pengadilan Niaga dapat memerintahkan lembaga yang bersifat mandiri untuk melakukan survei guna memperoleh kesimpulan mengenai terkenal atau tidaknya Merek yang menjadi dasar penolakan.

Aksesi Madrid Protokol sendiri oleh Pemerintah Republik Indonesia melalui Kementerian Hukum dan HAM dilakukan pada 2 Oktober 2017 dan mulai efektif berlaku pada tanggal 2 Januari 2018. Indonesia merupakan negara anggota madrid protokol yang ke-100. Sebagai negara anggota protokol madrid, pemerintah Indonesia dituntut untuk melakukan penyesuaian terhadap beberapa ketetuan protokol madrid ke dalam peraturan merek Indonesia, terutama untuk mengakomodir ketentuan terkait pendaftaran merek secara internasional pada 26 November 2016 akhirnya secara resmi pemerintah mencabut UU M erek Tahun 2001. Sebagaimana umumnya tantangan yang dihadapi oleh banyak negara ASEAN, Indonesia juga mengalami masalah dalam penegakan hukum terhadap pelanggaran merek (ERIA Working Group, 2015: 185-186). Di Indonesia, masih sangat mudah ditemukan perdagangan barang-barang yang menggunakan merek terkenal tanpa izin, dan sepertinya masyarakatpun memang menyukai barang-barang bermerek (meskipun itu palsu). Lemahnya penegakan hukum ini sendiri setidaknya secara teori dipengaruhi oleh beberapa faktor yaitu faktor UU, penegak hukum, fasilitas penegakan hukum, faktor masyarakat, dan faktor kebudayaan (Soekanto,2007: 5).

\section{Republik Demokratik Rakyat Laos}

Di bawah Decre No. 06-PM on Trademarks of Laos, perlindungan atas sebuah merek dagang dapat diberikan untuk tanda atau kombinasi dari tanda-tanda tersebut yang dapat membedakan produk barang atau jasa yang satu dengan yang lain. Oleh karena itu, tanda atau kombinasi tanda-tanda tersebut haruslah terdiri dari karakter-karakter yang berbeda dengan karakter-karakter dari merek dagang yang lain. Terkait merek terkenal, UU M erek Laos tidak mengatur mengenai merek terkenal. Perlindungan atas merek terkenal (well-known marks) tercantum dalam Law on Intellectual Property. Well-known mark sendiri diartikan sebagai "a trademark, which is widely recognized by the relevant sector within the territory of the Lao PDR, includ- ing where such knowledge is a result of promotion of the trade mark". Berdasarakan undang-undang ini, sebuah merek baru akan dilindungi dan mendapatkan sertifikat merek apabila diantaranya merek yang akan didaftarkan tersebut tidak sama identik dengan merek yang telah terkenal.

Selain hal tersebut di atas, sebuah merek dapat dianggap terkenal sepanjang memenuhi persyaratan-persyaratan sebagai berikut:

1. M erek tersebut harus dikenal luas diwilayah negara Laos;

2. Merek tersebut telah memiliki sirkulasi penjualan yang luas dibanyak negara;

3. Pemakaian merek yang terus-menerus;

4. Konsumen dosmestik mengenali dan mengetahui reputasi dari merek tersebut;

5. Dan beberapa pesyaratan lain seperti niat baik (good will) yang menyertai penggunaan merek tersebut seperti kualitas produk yang baik, service, pengetahuan masyarakat terhadap reputasi merek tersebut, volume penjualan, dan nilai investasi yang tinggi dari merek tersebut (Law on Intellectual Property of Lao PDR, Art. 16).

Laos juga merupakan salah satu negara anggota ASEAN yang telah bergabung dalam keanggotaan $\mathrm{M}$ adrid Protokol, tepatnya pada tanggal $7 \mathrm{M}$ aret 2016. Ketergabungan Laos dalam keanggotaan Madrid Protokol sendiri dilakukan dalam rangka mengoptimalkan perlindungan bagi merek asing di Laos, hal ini mengingat 95\% merek yang terdaftar di Laos merupakan merek asing, hanya $5 \%$ yang merupakan merek lokal (Watanabe, 2011: 105).

\section{Malaysia}

Sebuah merek dagang dapat berupa lambang, merek, judul, label, tiket, nama, tandatangan, kata, huruf, nomor, atau kombinasi dari hal-hal tersebut. Meskipun tidak disebutkan secara jelas, berdasarkan Jurisprudensi, bentukbentuk dan warna juga dapat dipertimbangkan sebagai merek dagang. Berdasarkan hukum merek M alaysia, suara atau aroma dapat didaftarkan sebagai merek dagang .

Sebagai salah satu negara anggota the Paris Convention dan TRIPsAgreement, pada tahun 2001 Malaysia melakukan amandemen the Trade Mark Act 1976 dalam rangka melindungi merek terkenal. Berdasarkan Pasal 13B the Trade 
Marks Regulation 1997, beberapa kriteria yang dapat digunakan untuk menentukan sebuah merek terkenal adalah:

1. Derajat pengetahuan dan pengenalan publik terhadap merek tersebut;

2. Durasi pemakaian dan luas wilayah dimana merek tersebut di gunakan;

3. Durasi dan luasjangkauan promosi merek, termasuk iklan atau presentasi umum di pameran-pameran atau exhibition;

4. Durasi dan banyaknya wilayah dimana merek tersebut terdaftar atau melakukan pendaftaran merek;

5. Catatan keberhasilan merek terkait untuk dilindungi sebagai merek terkenal;

6. dan nilai dari hal-hal yang terkait dengan merek.

\section{Myanmar}

Hingga saat ini, belum ada ketentuan hukum atau undang-undang terkait perlindungan bagi merek dagang atau ketentuan yang spesifik untuk mengatur pendaftaran merek dagang di negara M yanmar. Kekosongan hukum ini juga mengakibatkan belum terbangunnya sebuah fasilitas pencarian atau database merek, serta tidak adanya sistem keberatan yang dapat diajukan untuk mencegah sebuah merek ketika melakukan pendaftaran. Kondisi-kondisi tersebut di atas, menyebabkan sebuah merek dagang atau jasa, baik merek biasa maupun merek terkenal, sangat rentan digunakan tanpa izin oleh pihak lain.

Praktek yang berlaku di Myanmar saat ini, apabila seseorang Pemilik merek ingin melindungi mereknya maka yang bersangkutan diperbolehkan untuk mengumumkan kepemilikan (declaration of ownership) merek yang dimaksud. Selanjutnya berdasarkan the Registration Act pengumuman tersebut kemudian didaftarkan ke kantor the Registrar of Deeds and Assurances. A pabila telah terdaftar, disarankan declaration of ownership tadi kemudian di umumkan ke publik. Pengumuman dapat dilakukan melalui surat kabar bertaraf nasional dalam bentuk pemberitahuan peringatan (cautionary notice) untuk mengingatkan pihak lain agar tidak menggunakan merek tersebut secara melawan hukum.

Bilamana telah terjadi pelanggaran pemakaian merek yang tidak sah atau pemakai yang tidak beritikad baik (bad faith), upaya hukum yang dapat dilakukan antara lain:
1. Mengirimkan surat penghentian cease-and-desist yang memerintahkan pihak yang melanggar untuk menghentikan pelanggaran (infringement) tersebut;

2. M engajukan upaya pembatalan terhadap merek terdaftar yang tidak sah (infringed registered trademark);

3. Mengajukan penetapan sementara dari pengadilan dan membawa kasus ke pengadilan.

Pada saat melakukan upaya-upaya hukum tersebut diatas, sebagai pemilik merek yang bersangkutan harus bisa membuktikan bahwa dia adalah pemilik yang sah dengan menunjukan adanya penggunaan merek tersebut di M yanmar. Untuk membuktikan hal ini, pemilik merek haruslah menjual dan mendistribusikan produk-produknya dengan merek tersebut di M yamar. Selain itu, seorang pemilik merek juga harus bisa membuktikan adanya kerusakan reputasi akibat penggunaan tidak sah oleh pihak lain.

\section{Filipina}

Filipina merupakan salah satu negara ASEAN yang secara resmi telah menandatangani beberapa kesepakatan internasional terkait intelektual property, diantaranya WTO - GATT Treaty Uruguay Round (Annex C - Agreement on Trade Related Aspects of Intellectual Property Rights (TRIPS), Paris Convention, dan the M adrid Protokol. Dalam rangka penegakan hukum, Filipina juga telah memiliki undangundang khusus terkait merek yaitu Philippines Rules and Regulations On Trademarks, Service M arks, Tradenames and $M$ arked or Stamped Containers as amended by Office Order No.49 S.2006.

Terkait dengan merek terkenal, sebagaimana umumnya negara-negara di ASEAN yang menganut sistem registrasi first-to-file, agar mendapat pengakuan sebagai merek terkenal dan dilindungi oleh hukum merek Filipina, maka status tersebut haruslah dikeluarkan oleh lembaga yang berwenang, seperti pengadilan, Direktoral Jenderal, Biro Hukum kantor Hak Kekayaan Intelektual atau instansi pemerintah lainnnya yang berwenang untuk memeriksa dan mengadili setiap tindakan penegakan hukum. Status terkenal tersebut akan diberikan bilamana merek tersebut telah memenuhi beberapa parameter utama, diantaranya: derajat pengetahuan dan pengenalan publik terhadap merek tersebut, durasi pemakaian dan luas wilayah dimana merek 
tersebut di gunakan, durasi dan luas jangkauan promosi merek, termasuk iklan atau presentasi umum di pameranpameran atau exhibition, durasi dan banyaknya wilayah dimana merek tersebut terdaftar atau melakukan pendaftaran merek, catatan keberhasilan merek terkait untuk dilindungi sebagai merek terkenal, dan parameter lain sebagiamana yang disebutkan dalam Rule 102 Philippines Rules and Regulations On Trademarks, Service Marks, Tradenames and M arked or Stamped Containers.

\section{Singapura}

Sama halnya dengan Filipina, Singapura adalah salah satu negara ASEAN yang pada 31 Oktober 2000 secara resmi menjadi anggota the Madrid Protokol. Dalam penegakan hukum mereknya, Singapura dapat dikatakan merupakan negara yang tergolong selangkah lebih progresif dari negara ASEAN lain. Hukum merek Singapura sendiri yaitu Trade $M$ ark Act of Singapore hingga saat ini telah tercatat beberapa kali mengalami amandemen. Amandemen terakhir dilakukan pada tahun 2015.

M eskipun konsep merek terkenal telah diperkenalkan pada Amandment Trade M ark Act of Singapore of 1999, namun putusan pertama yang dibuat terkait merek terkenal di Singapura baru terjadi 8 (delapan) tahun kemudian, yaitu tahun 2007 pada kasusyang terjadi antara A manresort Limited and Another vs Novelty Pte.Ltd $\{2008\}$ 2SLR 32.

Untuk menentukan apakah suatu merek terkenal atau tidak, ada beberapa faktor yang digunakan oleh hakim lewat keputusannya, antara lain:

1. Derajat pengetahuan sektor terkait terhadap merek tersebut;

2. Luas wilayah penggunaan atau promosi atas merek tersebut;

3. Jenis pendaftaran atau permohonan pendaftaran dan hasil penilaian terkait merek tersebut.

Sebagai negara yang paling maju di kawasan ASEAN, permasalahan terkait intelektual properti di Singapura relatif rendah, kecuali untuk sistem penegakan hukum yang dianggap masih lemah, khususnya terkait kontrol perbatasan (ERIA Working Group, 2015: 186).
9. Thailand

Hukum merek Thailand mengakui tanda-tanda 3D (threedimensional signs) sebagai merek yang dapat didaftarkan dan dilindungi. Saat ini, Dewan Perwakilan Rakyat Thailand (The Thai Senate) sedang mengupayakan amandement terhadap beberapa ketentuan dalam Undang-Undang M erek. Amandemen Undang-Undang M erek ini nantinya akan mengakui suara dan wewangian (scent) dalam lingkup perlindungan rezim merek. Sebagai anggota the Paris Convention for the Protection of Industrial Property, rezim hukum merek di Thailand memberikan pengakuan terhadap 'right of priority'. Artinya apabila seseorang sebelum mendaftarkan mereknya di Thailand, yang bersangkutan terlebih dahulu telah mendaftarkan merek tersebut disalah satu negara angota the Paris Convention, maka tanggal pendaftaran akan merujuk pada tanggal pertama kali merek tersebut didaftarkan dinegara anggota the Paris Convention. Keaktifan Thailand dikancah internasional terkait perlindungan bagi merek diwujudkan melalui keanggotaannya di Madrid Protokol pada 7 November 2017.

Merujuk pada Surat Edaran M enteri tanggal 21 September 2004 tentang Ketentuan-ketentuan untuk M enentukan Sebuah M erek Terkenal, untuk menetapkan apakah sebuah merek terkenal ada beberapa hal yang harus digunakan, yaitu:

1. Berdasarkan itikad baik, merek tersebut telah digunakan, diiklankan sebagai merek produk barang atau jasa, atau produk lain;

2. Merek tersebut telah digunakan secara luas baik di Thailand atau negara lain;

3. Merek tersebut digunakan dan diterima oleh konsumen karena memiliki reputasi dan qualitas yang baik;

4. Merek tersebut digunakan baik oleh pemilik merek, penerima lisensi, atau pihak yang ditunjuk oleh pemilik merek, baik di Thailand ataupun luar negeri.

Terkait spesifik issue yang menjadi permasalahan hukum merek di Thailand, berdasarkan penelitian yang dilakukan oleh ERIA, biaya yang tinggi, waktu pemeriksaan yang terlalu lama, serta prosedur yang rumit, menjadikan Thailand sebagai negara yang mendapat perhatian khusus dari investor yang akan berinvestasi di sana (ERIA Working Group, 2015: 186) 


\section{Vietnam}

Berdasarkan Undang-Undang M erek Vietnam, yang dimaksud sebagai merek adalah tanda-tanda berupa huruf, kata, gambar termasuk hologram, atau kombinasi dari unsurunsur tersebut, yang diwujudkan dalam bentuk satu atau lebih dua warna. Lebih jauh, berdasarkan Undang-Undang merek Vietnam tanda/gambar 3D (three-dimensional signs/ shapes) dapat didaftarkan sebagai merek dagang. Namun demikian, merek dagang berupa suara dan aroma tidak dapat dilindungi oleh rezim merek. Vietnam sendiri selain terdaftar sebagai anggota the Paris Convention for the Protection of Industrial Property, the M adrid Agreement, demikian juga the M adrid Protocol.

Terkait dengan merek terkenal, Article 75 IP Law 2005 menjelaskan beberapa kriteria agar suatu merek dapat dinyatakan terkenal, yaitu:

1. Tingkat pengetahuan konsumen untuk mengenali suatu merek barang atau jasa pada sebuah iklan;

2. Luas wilayah pemasaran dari barang atau jasa dengan merek tersebut;

3. Lamanya merek tersebut telah digunakan;

4. Reputasi dari merek barang atau jasa tersebut dimasyarakat;

5. M erek tersebut telah terdaftar diberapa banyak negara;

6. Jumlah negara lain yang mengakui merek tersebut sebagai merek terkenal;

7. Penetapan harga, harga lisensi, atau kontribusi nilai investasi modal dari merek tersebut;

8. Purna jual dan perbaikan barang atas barang atau jasa yang telah dijual.

Namun demikian, meskipun IP Law 2005 telah menentukan kriteria penentuan merek terkenal, minimnya pasal terkait merek terkenal di IP Law 2005 juga di tenggarai menjadi sumber masalah bagi kepastian penegakan hukum merek di Vietnam. Hanya terdapat 3 pasal terkait merek terkenal dan ketentuan-ketentuan itupun sangat general. Hal ini berakibat pada penegakan hukum menjadi tidak efektif. lebih jauh, ketidaksinkronan beberapa peraturan hukum terkait seperti hukum acara, hukum persaingan usaha, hukum adat juga menciptakan sebuah kondisi sulit bagi aparat penegak hukum dalam melakukan penegakan hukum merek (Ngoc, 2011: 195).

\section{E. The Madrid Protocol: U paya M ewujudkan Sebuah Sistem Perlindungan Hukum yang Efektif Bagi Merek Terkenal di ASEAN}

The M adrid Protokol merupakan pengembangan dari Madrid Agreement 1891. Oleh karena pengembangan dari Madrid Agreement, konsep perlindungan bagi merek yang dikembangkan oleh the Madrid Protokol sama dengan konsep perlindungan yang dikembangkan dalam Madrid Agreement, yaitu one application, one number of registration, one renewal, one currency, and one document. Baik the Madrid Protokol ataupun the Madrid Agreement, keduanya sama-sama mengembangkan konsep satu kali pendaftaran merek untuk mendapatkan perlindungan hukum dibanyak negara, sering kali disebut sebagai sitem pendaftaran internasional/M adrid system. Setiap pihak di negara anggota yang telah melakukan pendaftaran dinegara asalnya cukup mengajukan permohonan pendaftaran internasional kepada WIPO International Berau melalui kantor merek dinegara asal. Nantinya, pendaftaran merek di negara asal akan berfungsi sebagai basic registration yang dapat digunakan sebagai dasar pengajuan pendaftaran merek internasional.

Dalam melaksanakan fungsinya tersebut, WIPO International Berau tidak melakukan pemeriksaan subtantive, WIPO International Berau hanya melakukan pemeriksaan formalitas termasukjuga biaya, pengklasifikasian merek yang didasarkan pada nice agreement clasiffication. Pemeriksaan detail terhadap pengajuan merek internasional termasuk kesamaannya dengan aplikasi atau pendaftaran pada negara asal dilakukan oleh kantor merek di mana pemohon tinggal, berbisnis atau berkewarganegaraan.

Terhadap pemeriksaan pengajuan pendaftaran merek internasional, apabila WIPO International Berau menemukan adanya ketidaksesuaian, WIPO International Berau akan memberitahukan hal tersebut kepada kantor merek negara asal untuk segera diperbaiki. A pabila semua telah sesuai maka WIPO International Berau akan mendaftarkan merek tersebut pada Internasional Register, mempublikasikan pada Berita Resmi WIPO, dan memberitahukan kantor merek negara asal, mengirimkan sertifikat pendaftaran pada pemegang, serta mengirim detail ke negara-negara tujuan. 
Nantinya, berdasarkan undang-undang mereknya, masingmasing negara tujuan akan memeriksa International Register. Apabila terdapat keberatan, maka negara tujuan akan memberitahukan hal tersebut ke W IPO International Berau yang selanjutnya akan disampaikan kepada pemegang merek. Penyelesaian selanjutnya akan dilakukan oleh agen/ konsultan merek lokal.

Sejatinya pendaftaran internasional tidak dikhususkan hanya untuk pendaftaran bagi merek terkenal, semua jenis merek diperkenankan untuk mendaftarkan mereknya menggunakan sistem ini. Terutama bagi merek-merek yang dalam strategi pemasarannya telah memiliki platform jangka panjang untuk pemasaran hingga keluar negara asal merek tersebut. Dengan sistem internasional ini, merek-merek yang bereputasi terkenal tentu akan sangat terbantu. Pemilik merek terkenal tidak perlu lagi mendaftarkan mereknya satu persatu ke negara tujuan pemasaran, dan otomatis tidak perlu lagi mengeluarkan biaya sewa konsultan hukum ditiap negara tujuan pemasaran.

Setelah lebih dari dua puluhan tahun disetujuinya the M adrid Protocol, hingga saat ini tercatat ada sebanyak 98 negara yang telah secara resmi menjadi anggota protokol. Sementara negara ASEAN yang menjadi anggota baru ada 4 negara, yaitu Brunei Darussalam, Laos, Filipina, dan Singapura. Setidaknya, dengan merujuk pada pendapat WIPO, dengan meratifikasi dan mengimplementasikan the M adrid Protokol dalam sistem hukum national, suatu negara akan mendapatkan beberapa keuntungan, antara lain:

1. Mudah (convinient): dengan mengunakan madrid sistem, untuk mendapatkan perlindungan internasional dibanyak negara, pemilik merek cukup sekali saja mendaftarkan mereknya yang dilakukan di negara asal;

2. Lebih hemat biaya (cost effective): dengan melakukan pendaftaran internasional itu berarti pendaftar telah melakukan pendaftaran di banyak negara. Pendaftar telah melakukan penghematan biaya khususnya biaya terjemahan bahasa, dan biaya pengurusan kelengkapan administratif di banyak negara;

3. Cakupan geografis yang luas (broad geographic coverege): dengan meratifikasi the Madrid protocol, satu pendaftaran internasional dapat memberikan perlindungan merek hingga 117 negara.
M eskipun pada lingkup regional mayoritas negara ASEAN belum banyak yang secara resmi menjadi anggota dan berkomitmen untuk menerapkan sistem one application, one number of registration, one renewal, one currency, and one document dalam rezim hukum merek dinegaranya, namun demikian dalam rangka membangun sebuah sistem perlindungan hukum merek yang efektif, khususnya untuk merek terkenal (well known marks), negara ASEAN dan negara di dunia perlu kiranya untuk segera mengintegrasikan spirit dari the M adrid Protokol ini ke dalam sistem hukum nasionalnya.

\section{V.KESIM PULAN DAN SARAN}

\section{A. Simpulan}

Dalam praktek sistem pendaftaran hak merek yang bersifat teritorial seringkali menjadi tantangan tersendiri dalam penegakan hukum merek. Tuntutan pendaftaran harus dilakukan disetiap negara tujuan menjadikan merek terkenal sangat rentan untuk dimanfaatkan tanpa izin oleh pihakpihak yang tidak berhak. Secara umum sistem pelindungan merek negara-negara ASEAN menggunakan sistem first to file. Sistem ini mengharuskan kewajiban pendaftaran bagi merek terkenal agar dilindungi disetiap negara ASEAN. Dengan mengimplementasi sistem pendaftaran internasional (M adrid system) yang ditawarkan oleh M adrid Protokol, yaitu single application, one number of registration, one renewal, one currency, and one document pemilik merek cukup sekali melakukan pendaftaran di salah satu negara ASEAN untuk mendapatkan perlindungan diseluruh negaranegara ASEAN. Secara otomatis pemilik merek yang mendaftar dengan menggunakan Madrid system akan mendapatkan perlindungan diseluruh negara anggota Madrid Protokol yang saat ini berjumlah 167 negara. Singkatnya, dengan Madrid system hambatan biaya, hambatan prosedural, dan hambatan teritorial bukan lagi menjadi masalah bagi para pemilik merek terkenal.

\section{B. Saran}

Sebagai salah satu negara anggota M adrid Protokol, Pemerintah Indonesia perlu segera mengesahkan peraturan pelaksana terkait permohonan pendaftaran merek inter- 
nasional, dan insfrastruktur kebijakan lainnya. Selain itu perlu dibentuk pula tim protokol madrid yang bertugas secara khusus memeriksa dan menangani permohonan merek tradisional.

\section{DAFTAR PUSTAKA}

A nonim, 2013, Trade M ark Protection in Southeast A sia, V ietnam, Rouse \& Co. International.

Ali, Chaudhry Asfand, 2008, A nalysis On The Impact of $M$ adrid Protocol For The Economies of D eveloping Countries, Tokyo, Japan Patent Office \& Asia-Pacific Industrial Property C entre, Japan Institute of Invention and Innovation.

D egelsegger, Alexander, Svend Otto Remøe, \& Rudie Trienes, 2016, ASEA N Economic Community and Intellectual Property Rights: An A ssessment of F ramework C onditions For Innovation. Dalam https:/ / W ww.Knaw.NI/ Shared/Resources/Inter national/Bestanden/ A seaneconomiccommunityandintellectual propertyrights.Pdf.

D irektorat Jenderal Kerja Sama Perdagangan Internasional, 2011, Informasi U mum: M asyarakat Ekonomi A sean, C ommunity In A Global Community Of N ations, Jakarta, Kementerian Perdagangan Republik Indonesia.

ERIA Working Group, 2015, Problems and Challenges of Intellectual Property Systems in ASEAN, in Reforming the Intellectual Property System to Promote Foreign Direct Investment in A SEA N, Jakarta: ERIA.

Ibrahim, Johnny, 2006, Teori dan M etodologi Penelitian H ukum N ormatif, Bandung, PT Remaja Rosdakarya.

Intellectual Property O ffice of Singapore, 2012, Trademarks infopack of Singapore. Dalam https:/ / W ww.H g.O rg/ Article.Asp?l $d=5086$.

H idayati, Nurul dan Naomi Yuli Ester S, 2017, U rgensi Perlindungan $M$ erek M elalui Protokol M adrid (Trademark Protection U rgency Through The M adrid Protocol, Jurnal legislasi indonesia,), Vol. 14 No. 02

Lackert, Clark W dan M aren C Perry, 2008, Protecting W ellKnown A nd Famous M arks: A G lobal Perspective, Building and Enforcing Intellectual Prodaperty Value 2008, U nited Kingdom, G lobal White Page Ltd.

Setianingrum, Reni Budi, 2016, M ekanismePenentuan N ilai Ekonomis dan Pengikatan $\mathrm{H}$ ak C ipta Sebagai $\mathrm{O}$ bjek Jaminan Fidusia, Jurnal M edia H ukum, Vol. 23 No. 2

Soekanto, Soerjono dan Sri Mamuji, 2003, Penelitian H ukum N ormatif Suatu Tinjauan Singkat, Jakarta, Raja G rafindo Persada.

Soekanto, Soerjono, 2007, Sosi ologi Suatu Pengantar, Jakarta,
PT Raja G rafindo Persada.

Tam Phan N goc, 2011, Well-K nown Trademark Protection. A Comparative Study B etween The Laws of The European $U$ nion And V ietnam. Sweden, Lund U niversity.

Thu, Hà Thi N guyet, 2010, Well-K nown Trademark Protection R eference To The Japanese Experience. Dalam $\mathrm{H}$ ttp:// W ww.W ipo.Int/ Export/ Sites/W ww/ A boutW ipo/ En/ O ffices/Japan/ Research/Pdf/Vietnam_2010.Pdf.

W IPO , 2000, Joint Recommen dation Concerning Provisions $0 \mathrm{n}$ The Protection of W ell-K nown M arks, G eneva, WIPO.

W IPO , 2016, G uide(To The International R egistration of M arks $U$ nder The M adrid Agreement(And The M adrid Protocol, Geneva, WIPO.

Watanabe, Shuo, 2011, Trends in D evelopment and Issues Related to IP Systems in Three G M S C ountries: C ambodia, Lao PDR and Thailand, Japan, Ritsumeikan U niversity

\section{Peraturan Perundang-Undangan}

Law C oncerning M arks, Trade $N$ ames and Acts of U nfair Competition of the Kingdom of $\mathrm{C}$ ambodia

$M$ adrid Protocol Concerning The International Registration Of Marks

M yanmar Registration Act No. 16 of 1908

Protocol Relating to the M adrid Agreement Concerning the International Registration of $M$ arks

M alaysia Trademark Act 175 of 1976 as Amended by Act A 1138 of 2002

Philippines Rules and Regulations on Trademarks, Service $M$ arks, Tradenames and $M$ arked or Stamped C ontainers as Amended by 0 ffice O rder N 0.49 S.2006

Regulation N 0.466/Stea-Pmo of Prime M inister on R egistration of Trademarks of Lao People's D emocratic Republic

Trademark Law Treaty of Singapore year 1994

Trademark Act B.E. 2534 (1991) as A mended by TheTrademark Act (N O. 2) B.E. 2543 (2000) of Thailand

Trade $M$ arks $A$ ct of Brunnai D arussalam

Undang-U ndang Republik Indonesia Nomor 20 Tahun 2016 Tentang M erek dan Indikasi Geografis 